\title{
A Rare Cause of Abdominal Pain in Adults: Meckel's Diverticulitis
}

\author{
Usman Pirzada Hassan Tariq Sara Azam Kishore Kumar Anil Dev \\ Department of Medicine, BronxCare Hospital Center, Bronx, NY, USA
}

\section{Keywords}

Meckel's diverticulitis · Meckel's diverticulum · Abdominal pain · Meckel's scan

\begin{abstract}
A 42-year-old man presented to the emergency room with complaints of periumbilical abdominal pain. A contrast-enhanced computed tomography revealed mucosal thickening in the small bowel of the right abdomen. There was a fairly large small bowel diverticulum associated with this segment. Findings were suggestive of small bowel diverticulitis or possibly focal enteritis. A Meckel's diverticulum scan was diagnostic of Meckel's diverticulum. The patient was then immediately taken to the operating room for emergency laparotomy and was intra-operatively found to have a thickened Meckel's diverticulitis with adjacent small bowel obstruction. Meckel's diverticulectomy was performed in continuity with the adjacent inflamed small bowel. The patient had a stable postoperative course without any complications and was discharged within 10 days. At the 3-month follow-up, the patient was well and remained asymptomatic.




\section{Case Reports in Gastroenterology} \begin{tabular}{l|l}
\hline Case Rep Gastroenterol 2018;12:709-714 \\
\hline DOI: 10.1159/000494752 & $\begin{array}{l}\text { @ 2018 The Author(s). Published by S. Karger AG, Basel } \\
\text { www.karger.com/crg }\end{array}$
\end{tabular}

Pirzada et al.: A Rare Cause of Abdominal Pain in Adults: Meckel's Diverticulitis

\section{Introduction}

Meckel's diverticulum (MD) is the most common congenital anomaly of the gastrointestinal tract, which results from incomplete obliteration of the vitelline duct, leading to the formation of a true diverticulum of the small intestine [1]. Meckel's diverticula are uncommon and often clinically silent, particularly in adults. Asymptomatic MD may be discovered during abdominal exploration for the evaluation of unrelated pathology. At times, Meckel's diverticula are found incidentally on diagnostic imaging. When symptomatic, MD may present with abdominal pain or symptoms of gastrointestinal bleeding or bowel obstruction [1].

There is probably no familial predisposition for MD, although a few cases of occurrence within the same family have been reported [2]. The prevalence of MD is increased in children born with a major malformation of the umbilicus, alimentary tract, nervous system, or cardiovascular system, in descending order [3]. Several risk factors for developing symptomatic MD have been identified: male sex, age $<50$ years, diverticulum length $>2 \mathrm{~cm}$, or those that contained heterotopic mucosa [4]. When 2,3 , or 4 of these criteria were met, the proportion of symptomatic MD increased to 25,42 , and $70 \%$, respectively [5].

We report a case of Meckel's diverticulitis in a 42-year-old male who presented with abdominal pain.

\section{Case Presentation}

A 42-year-old man with a medical history of hypertension presented to the emergency room of our hospital with complaints of periumbilical abdominal pain that started while he was eating food that he bought from the supermarket. The pain was severe, 10/10 in intensity, not radiating, sharp, with no aggravating or relieving factors. The abdominal pain was associated with nausea and multiple episodes of nonbloody, bilious vomiting.

On physical examination, the patient was afebrile $\left(98.3^{\circ} \mathrm{F}\right)$ and hemodynamically stable with a pulse rate of 92 beats per minute, respiratory rate of 17 breaths per minute, blood pressure of $148 / 107 \mathrm{~mm} \mathrm{Hg}$, and oxygen saturation of $95 \%$ on room air. The abdomen was soft, with periumbilical tenderness and audible bowel sounds.

Laboratory testing revealed leukocytosis with neutrophilia and a lactate of $1.9 \mathrm{~mm} / \mathrm{L}$. Contrast-enhanced computed tomography (CT) revealed mucosal thickening in the small bowel of the right abdomen. There was a fairly large small bowel diverticulum associated with this segment. Findings were suggestive of small bowel diverticulitis or possibly focal enteritis (Fig. 1). The patient was initially managed conservatively with intravenous fluids, nil per os, and intravenous antibiotics. Later, a MD scan with flow study showed a focus of increased uptake to the right of the midline below the stomach corresponding to the area of abnormality described on the CT scan. Subsequent static imaging demonstrated a continued increase in activity in the jejunum beyond this point, which was diagnostic of MD (Fig. 2). The patient was then immediately taken to the operating room for emergency laparotomy and was intra-operatively found to have a thickened Meckel's diverticulitis with adjacent small bowel obstruction. Meckel's diverticulectomy was performed in continuity with the adjacent inflamed small bowel. The pathology report later revealed an MD with diffuse ulcer, suppurative 
diverticulitis, abscess, and acute serosal inflammation with the margins of the small intestine free of inflammation.

The patient had a stable postoperative course without any complications and was discharged within 10 days. At the 3-month follow-up, the patient was well and remained asymptomatic.

\section{Discussion}

The total lifetime rate of complications in MD is widely accepted at $4 \%[6,7]$ with a maleto-female ratio of 3:1 [6-9]. The largest study, by Ymaguchi et al. [8], including 600 patients, 287 of whom were symptomatic, showed the complication rates presented in Table 1. Diverticulitis and perforation occurred at a combined rate of almost $20 \%$ and were often indistinguishable from acute appendicitis until visualization in the operating room [8]. Moore and Johnston [9] reported that $40 \%$ of patients in a series of 50 patients with MD had a preoperative diagnosis of acute appendicitis. Initially, a fecalith obstructs the diverticulum, leading to inflammation, necrosis, and eventual perforation. In our patient, we were able to obtain a Meckel's nuclear scan to assist in the preoperative diagnosis as the patient was hemodynamically stable.

MD is usually clinically silent but can be found incidentally or can present with a variety of clinical manifestations. About $25-50 \%$ of patients with symptomatic disease are $<10$ years of age. It is believed that children present more often than adults with bleeding and adults more often than children with symptoms of small bowel obstruction [1]. However, the available data is not conclusive on this point, thus all varieties of symptomatic presentations should be considered in any age group [5]. Primarily, MD should be suspected in children with painless lower gastrointestinal bleeding, children with intussusception, particularly recurrent or atypical intussusception, patients with features of acute appendicitis, particularly when the appendix has already been removed, and adults with gastrointestinal bleeding with no identifiable source on upper endoscopy or colonoscopy. For a definite diagnosis of MD, a Meckel's scan, mesenteric arteriography, double-balloon enteroscopy, capsule endoscopy, or abdominal exploration is usually required depending on the initial clinical presentation [10].

Surgical resection of symptomatic MD is the standard of care. Surgical options include simple diverticulectomy or ileal resection with the later procedure preferred when there is evidence of severe inflammation, perforation, or tumor [5]. Laparoscopic procedures can be performed without increased risk of complications by experienced surgeons [11-14]. Any associated attachments to the abdominal wall should be removed. The incidence of early postoperative complications is $12 \%$, including mainly surgical site infection (3\%), prolonged ileus (3\%), and anastomotic leak (2\%), with a mortality rate of $1.5 \%$ [8]. In the case of our patient, Meckel's diverticulectomy was performed in continuity with the adjacent inflamed small bowel with recovery and hospital discharge within 10 days of presentation.

In patients with symptomatic MD, the challenge presents itself in early diagnosis and prompt surgical treatment. As it is a rare condition, a high index of suspicion is necessary as clinical presentation is variable, differential diagnosis is not straightforward, and imaging techniques may not be useful at times. To overcome these difficulties, a CT scan with oral and intravenous contrast (if possible) is recommended. In the case of our patient, we were able to 
make the diagnosis preoperatively, perform the surgery promptly, and were able to avoid complications of delayed surgical intervention.

\section{Statement of Ethics}

This case report was exempted from our Institutional Review Board as per its policy.

\section{Disclosure Statement}

None of the authors have any financial conflicts of interest. All authors have confirmed that the article is not under consideration for review at any other journal.

\section{Author Contributions}

All authors have made contributions to the article and have reviewed it before submission.

\section{References}

1 Sagar J, Kumar V, Shah DK. Meckel's diverticulum: a systematic review. J R Soc Med. 2006 Oct;99(10):501-5.

2 Passarge E, Stevenson RE. Meckel's diverticulum. In: Stevenson RE, Hall JE, editors. Human malformations and related anomalies, second edition. Oxford: Oxford University Press; 2006. p. 1111.

3 Simms MH, Corkery JJ. Meckel's diverticulum: its association with congenital malformation and the significance of atypical morphology. Br J Surg. 1980 Mar;67(3):216-9.

4 Mackey WC, Dineen P. A fifty year experience with Meckel's diverticulum. Surg Gynecol Obstet. 1983 Jan;156(1):56-64.

5 Park JJ, Wolff BG, Tollefson MK, Walsh EE, Larson DR. Meckel diverticulum: the Mayo Clinic experience with 1476 patients (1950-2002). Ann Surg. 2005 Mar;241(3):529-33.

6 Leijonmarck CE, Bonman-Sandelin K, Frisell J, Räf L. Meckel's diverticulum in the adult. Br J Surg. 1986 Feb;73(2):146-9.

7 Soltero MJ, Bill AH. The natural history of Meckel's diverticulum and its relation to incidental removal. A study of 202 cases of diseased Meckel's diverticulum found in King County, Washington, over a fifteen year period. Am J Surg. 1976 Aug;132(2):168-73.

8 Ymaguchi M, Takeuchi S, Awazu S. Meckel's diverticulum. Investigation of 600 patients in Japanese literature. Am J Surg. 1978 Aug;136(2):247-9.

9 Moore T, Johnston AO. Complications of Meckel's diverticulum. Br J Surg. 1976 Jun;63(6):453-4.

10 He Q, Zhang YL, Xiao B, Jiang B, Bai Y, Zhi FC. Double-balloon enteroscopy for diagnosis of Meckel's diverticulum: comparison with operative findings and capsule endoscopy. Surgery. 2013 Apr;153(4):54954.

11 Cullen JJ, Kelly KA, Moir CR, Hodge DO, Zinsmeister AR, Melton LJ 3rd. Surgical management of Meckel's diverticulum. An epidemiologic, population-based study. Ann Surg. 1994 Oct;220(4):564-8.

12 Groebli Y, Bertin D, Morel P. Meckel's diverticulum in adults: retrospective analysis of 119 cases and historical review. Eur J Surg. 2001 Jul;167(7):518-24.

13 Peoples JB, Lichtenberger EJ, Dunn MM. Incidental Meckel's diverticulectomy in adults. Surgery. 1995 Oct;118(4):649-52.

14 Rivas H, Cacchione RN, Allen JW. Laparoscopic management of Meckel's diverticulum in adults. Surg Endosc. 2003 Apr;17(4):620-2. 


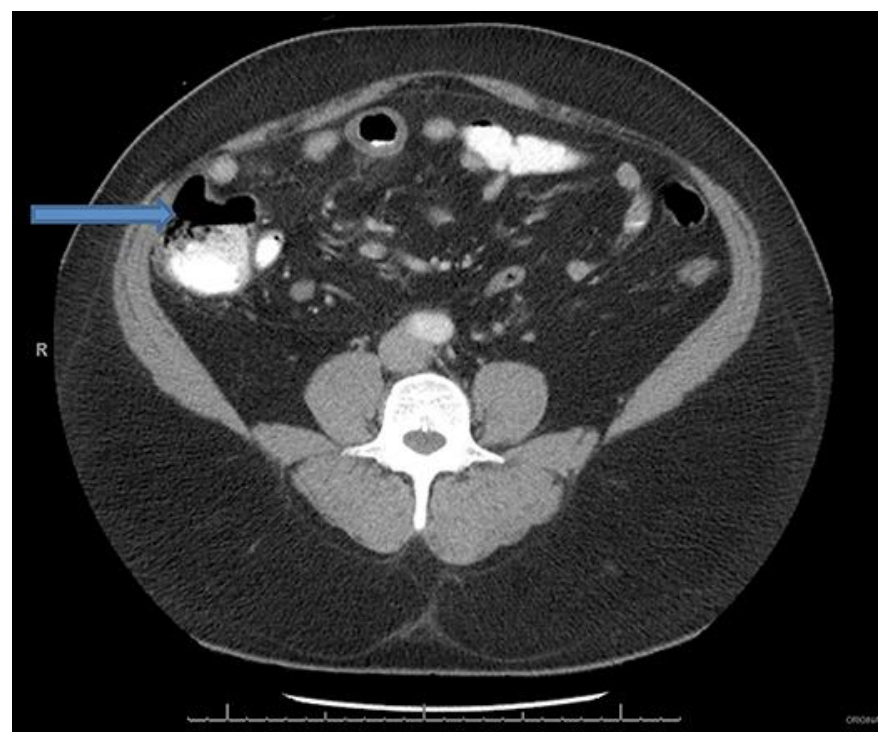

Fig. 1. Computed tomography of the abdomen and pelvis with contrast material: mucosal thickening in the small bowel of the right abdomen. There is a fairly large small bowel diverticulum associated with this segment.
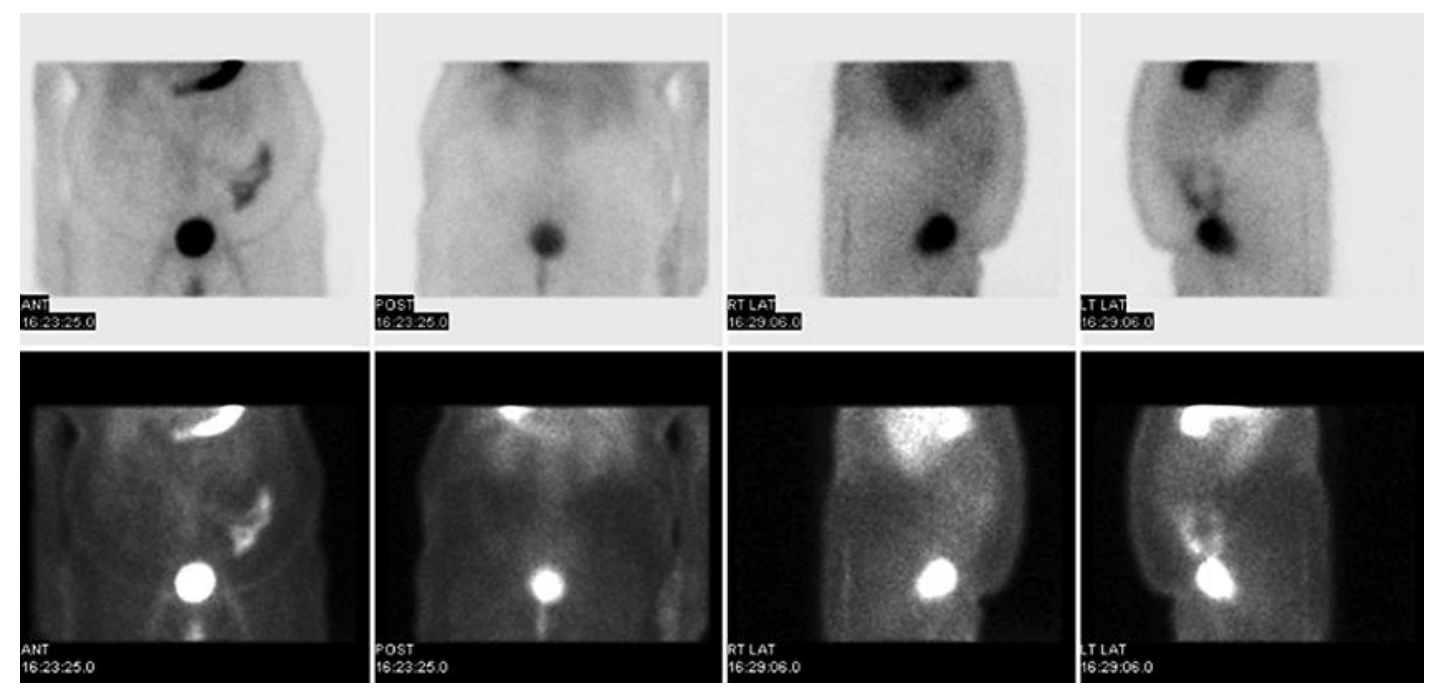

Fig. 2. Nuclear medicine Meckel's scan: following intravenous administration of $15 \mathrm{mCi}$ technetium-99m pertechnetate, rapid sequence imaging of the abdomen was obtained. Subsequent 1-min-interval static imaging of the abdomen was obtained in anterior projections up to $60 \mathrm{~min}$, following which static imaging in the anterior-posterior/posterior-anterior and lateral projections was obtained. The flow study shows a focus of increased uptake to the right of the midline. Subsequent static imaging obtained up to 60 min shows continued increased activity in the proximal jejunum beyond the area of initially increased uptake. 
\begin{tabular}{l|l}
\hline DOI: 10.1159/000494752 & (c) 2018 The Author(s). Published by S. Karger AG, Basel
\end{tabular} www.karger.com/crg

Pirzada et al.: A Rare Cause of Abdominal Pain in Adults: Meckel's Diverticulitis

Table 1. List of complications and their incidence according to a study by Ymaguchi et al. [8]

\begin{tabular}{lc} 
Complications & Incidence, \\
& $\%$ \\
\hline Obstruction & 36.5 \\
Intussusception (often presents as obstruction) & 13.7 \\
Inflammation/diverticulitis & 12.7 \\
Perforation & 7.3 \\
Hemorrhage & 11.8 \\
Neoplasm & 3.2 \\
Fistula & 1.7 \\
\hline
\end{tabular}

